\title{
SIMULACRO E REVERSIBILIDADE NO DISCURSO RELIGIOSO “NEOPENTECOSTAL"
}

André Corten, GRIPAL, UQAM ${ }^{1}$

Ao afirmar que o "sagrado é o simulacro instituído do Abismo", Castoriadis funda em um nível não discursivo a afirmação que encontramos no título do ensaio e em inúmeros subtítulos de Jaçanã Ribeiro: "o simulacro da alteridade". Em sua tese, o estudo do simulacro se baseia na concepção de Eni Orlandi, para quem o discurso religioso é um discurso autoritário, pois há somente ilusão de reversibilidade entre o locutor e o ouvinte. Ao longo de seu trabalho, Ribeiro busca mostrar a validade dessa posição analisando o discurso de exorcismo da Igreja Universal do Reino de Deus (IURD).

Uma primeira parte substancial é consagrada à apresentação de conceitos familiares à escola francesa de análise do discurso e notadamente ao projeto traçado por Foucault e Pêcheux e sistematizado por Maingueneau. Essa primeira parte é estratégica porque são esses conceitos que vão permitir ao autor chegar à tese da não-reversibilidade. É a partir desses conceitos que é igualmente possível recusar em parte essa mesma tese. Mesmo reconhecendo a qualidade da análise, será um exercício de "advogado do diabo" que desenvolverei nesse pequeno texto.

Tudo começa por um a priori. Para o autor, o discurso da IURD está em relação interdiscursiva privilegiada com o discurso das religiōes afro. Certamente, do ponto de vista do autor, não se trata de um a priori, pois a escolha de isolar esse espaço discursivo repousa, segundo ele, sobre a literatura antropológica e sociológica, em particular brasileira. É a partir desse primeiro ponto que será apresentada uma análise crítica do texto de Ribeiro.

${ }^{1}$ Professor da UQAM = Universidade de Quebec, em Montreal, Canadá, e dirigente do GRIPAL (www.gripal.ca) = Groupe de Recherche sur les Imaginaires Politiques en Amérique latine (Grupo de Pesquisa sobre os imaginários políticos na América Latina). Este texto foi traduzido do francês por Jaçanã Ribeiro. 
Nascida há um quarto de século, a Igreja Universal conheceu uma expansão acelerada não somente no Brasil, mas no mundo. Certamente, não devemos exagerar sua importância. No Brasil, ela conta com dois milhôes de fiéis e, no resto do mundo, divididos em 80 países, com um milhão. No Brasil, ela se encontra bem atrás da Assembléia de Deus (de origem e modelo especificamente brasileiros), que conta com oito milhões de adeptos e, no plano mundial, bem atrás da Assembléia de Deus (de origem americana), que em todas suas filiais reúne 35 milhões de crentes. Ela não é assim a igreja multinacional mais importante proveniente do Sul.

A Igreja Universalé importante porque ela introduz no pentecostalismo uma orientação nova tanto em relação às mídias e ao dinheiro quanto em sua capacidade de se articular a um individualismo próprio a um terceiro mundo urbanizado. Ela prefigura desse triplo ponto de vista uma evolução geral do pentecostalismo. Mesmo que não se disponha de dados sobre sua evolução quantitativa desde 2000, sua presença no universo urbano, notadamente pela edificação de catedrais, testemunha posses consideráveis e sucesso de visibilidade.

Ao invés de propor a seus adeptos uma atitude de retração do mundo e de constituição de neo-comunidades, a Igreja Universal se coloca em posição de conquista do mundo e de "sua liberação do jugo de Satâ". Essa perspectiva é confirmada em uma visão planetária e justifica a prioridade dada à expansão multinacional. Se é verdade que em muitos dos 80 países a presença da Universal é puramente nominal, ela se tornou um componente notório do universo religioso de no mínimo sete países: África do Sul, Moçambique, Costa do Marfim, Argentina, Venezuela, Portugal, Estados Unidos. Além disso, ela continua seu esforço de inserção em regióes da Ásia pouco permeáveis ao cristianismo.

A Igreja Universal capitaliza os resultados do paradoxo das sociedades modernas. De um lado, essas são marcadas por um grande relativismo (e a Igreja Universal adapta-se através de uma grande tolerância frente à evolução dos costumes e das técnicas) e, de outro, faz largo uso de novas formas de maniqueísmo e de u ma visão do mundo - na ficção como na política de uma guerra entre o Bem e o Mal. Nas condições de vida das zonas 
pauperizadas das vilas do terceiro mundo, um novo individualismo toma forma, ele é constituído paradoxalmente de pragmatismo e de espera de milagres. Esse oximoro leva a uma concepção de banalização do milagre. $\mathrm{O}$ individualismo das populações pauperizadas do terceiro mundo é também muito maleável aos espetáculos tornados habituais em razão da intrusão massiva das mídias televisivas e radiofônicas nos espaços mais residuais no plano mesmo do habitat. Pode-se viver amontoado com cinco pessoas em uma mesma peça, mas compartilhar cada uma a sua conta a dependência face às "telenovelas", os documentários e os noticiários, sendo o nível de ficção entre esses três materiais eventualmente recebido de maneira diversa. Vive-se com a telenovela e a cena política é percebida como um mundo de ficção. Nessa perspectiva, as malas abarrotadas de dinheiro da atualidade política brasileira do verão de 2005 não surpreendem.

O sucesso da Igreja Universal se deve em parte a sua capacidade de "adequar-se" aos traços contraditórios do individualismo do terceiro mundo. É em relação a esse e nessa dependência face ao espetáculo que tem lugar o discurso "iurdiano" de exorcismo pela mobilização do discurso das religiōes afro. Reduzir esse discurso somente a essa relação polêmica pode desfigurar completamente o sentido dessa mobilização e colocar a IURD no domínio de um arcaísmo, com o apoio de certos antropólogos que se sentem tranqüilizados por encontrarem-se em seu terreno habitual.

De natureza complexa, mesmo contraditória, a realidade do individualismo do terceiro mundo captada pela Igreja Universal oferece um desafio à análise.Desse modo parece plenamente justificada a tentativade decodificar o funcionamento do discurso da IURD fazendo uso de categorias da análise do discurso tais como prática discursiva, heterogeneidade discursiva, formação discursiva, etc. Entretanto não devemos parar no plano dos locutores e concluir, a partir daí, a não-reversibilidade do discurso. Isso parece evidente, mas é da construção do conceito de formação discursiva que depende a boa interpretação dos conceitos de locutor e enunciador.

$\mathrm{O}$ autor retoma a redefinição que Pêcheux faz do conceito foucaultiano de formação discursiva. Para Foucault, a formação discursiva é aquilo que dá conta do aparecimento de um enunciado e não outro em determinado 
lugar, mas sem que esse aparecimento seja fixado por uma ortodoxia, ou seja, por uma coerência ao nível da história das idéias (no caso aqui uma teologia determinada). Portanto, com relação a uma ideologia e a uma posição ideológica.Esse aparecimento é, ao contrário,regido por uma regularidade na dispersão. Essa regularidade concerne ao funcionamento enunciativo do discurso e portanto às posições enunciativas que ele distribui.

A definição de Foucault fora concebida para dar conta dos cortes das "ciências humanas". Ela está de fato exposta em A Arqueologia do Saber. Estimulante nessa perspectiva, ela se mostra menos diretamente operatória quando a aplicamos a qualquer tipo de discurso. Ela implica de fato a heterogeneidade constitutiva do discurso: de uma vez, ele não tem um só sentido e, entretanto, não tem qualquer sentido.

Pêcheux tentou dar um conteúdo a essa dispersão relacionando-a a posições ideológicas. Retomo aqui a citação feita por Ribeiro: "O sentido de uma palavra, de uma expressão, de uma proposição, etc, não existe por si mesmo (ou seja, em uma relação transparen te como a literalidade do significante), mas, ao contrário, é determinado por posições ideológicas em jogo no processo sócio-histórico no qual essas palavras, expressões, proposições são produzidas (ou seja, reproduzidas) (...) as palavras, expressões, proposições, etc. mudam de sentido segundo as posições daqueles que as empregam".

Com Pêcheux, a dispersão é reduzida a posições ideológicas e a processos de substituição. Para Pêcheux, retomado por Ribeiro, os processos discursivos são um "sistema de substituiçōes, de paráfrases, de sinonímias, etc., que funcionam en tre elementos lingüísticos - significantes - em u ma formação discursiva dada”.

Dois elementos vêm enriquecer essa perspectiva, aquele do préconstruído, introduzido por Henry e Pêcheux, e aquele do dialogismo, concebido por Bakhtin e que Courtine ilustrou em seu estudo do discurso comunista dirigido aos Cristãos. Em uma interpretação, de fato, restritiva. Os pré-construídos podem ser interpretados como um instrumento para cerrar a regularidade das dispersões. Distingue-se em efeito duas dimensões do discurso: de um lado, o pré-construído, aquilo sobre o que o falante se 
apóia, que ele apresentacomo já lá e que é substratoà asserçãodo enunciador; de outro o construído, aquilo que o enunciador pretende colocar. O préconstruído escapa de uma lógica da argumentação e mesmo de narração. Ele é da ordem da dispersão. Em segundo lugar, há o dialogismo. Interpretado de maneira estrita, diálogo com apenas um outro discurso supostamente homogêneo, entra nas regras de argumentação e se afasta da abordagem da dispersão.

Ribeiro insiste fortemente na necessidade de pensar em termos de interdiscurso, mas essa noção é tomada a partir de formações discursivas definidas de início com um certo grau de homogeneidade fixada pelas posiçoes ideológicase isso poderia conduzira tratar a heterogeneidade discursiva em termos de "contradição-subordinação-d esigualdade entre formações ideológicas em conflito". Entretanto, essa não é a direção em que se orienta Ribeiro, uma vez que distingue a formação discursiva 1 FD1 (discurso da IURD) e a FD2 (discurso das religiōes afro). Isso poderia ter sido interessante para melhor compreender a significação ideológicado sucessoda IURD e de sua maneira de dar um estatuto às entidades das religiōes afro. Com as reservas mencionadas. Mas não é essa a escolha do autor. Entretanto, a questão é tratada indiretamente uma vez que o estatuto da realidade das entidades religiosas afro é reconhecido como um pré-construído. A partir daí, a FD2 poderia ser tratada em termos de dispersão de FD1. Porém também não é esse o caminho seguido.

A FD2 é abordada sobretudo em uma démarche que busca demonstrar o funcionamento do simulacro. Pode-se mesmo considerar que a escolha dessa démarche é essencial para a demonstração. Entretanto, essa escolha limita ao mesmo tempo a concepção de simulacro que aparece tal qual um boneco durante o espetáculo, animado pelos dedos do manipulador da marionete, depois deixado caído sobre o solo. Estamos longe de uma concepção forte de religião como simulacro tal qual a desenvolvida pela abordagem de Castoriadis, que encontramos resumida no trecho seguinte:

"O Abismo é anunciado, tornado possível na e pela religião, e, ao mesmo tempo, essencialmente ocultado. Também é assim com a Morte no

Debates do NER, Porto Alegre, ano 6, n. 7, P. 115-124, Jan./Jun. 2005 
cristianismo, por exemplo: presença obsedante, lamentação interminável e, ao mesmo tempo, denegação absoluta, pois essa Morte não é uma morte verdadeira, sendo o acesso a uma outra vida... O sagrado é o simulacro instituído do Abismo" (Casto riadis, 1986, pp. 522-523).

Observemos de mais perto a demonstração limitada do simulacro. Ribeiro trabalha com um corpus de dez transcrições dos cultos de terça-feira (sessão do descarrego - de liberação) ou de sexta-feira (sessão de libertação) de cinco igrejas de localização diferentes (mas todas situadas na região de Porto Alegre). Detalhe de pesquisa, não somos informados se as gravações foram realizadas com a autorização da igreja. Podemos entretanto supor que a presença reconhecida e eventualmente autorizada das observações não mude nada o teor das amostras. Nas igrejas escolhidas, são principalmente os bispos que parecem ministrar os cultos. O "sujeito" iden tificado é conseqüentemente o "sujeito-bispo". Dos 4000 templos da IURD no Brasil, não mais de uma centena têm bispos como responsáveis pela condução do culto. Por que então falar de bispo? Esse fator não introduz uma certa representatividade?

A divisão do ritual de exorcismo é realizada em quatro seçóes: invocação do Espírito Santo, invocação do Encosto (a força que possui aquele que será exorcizado), ato de exorcismo e confirmação da liberação. Essas seções são notadamente caracterizadas pelo ato de linguagem de um de seus sujeitos. De fato, teoricamente, não se trata de "sujeitos", mas de posiçōes de sujeito. São as condições de enunciação que distribuem as posições, mas no corte do corpus, a posição-sujeito se torna sujeito e o sujeito, o locutor.

Cinco sujeitos são distinguidos: o sujeito bispo ou pastor, sujeito fiel, o sujeito obreiro, o sujeito encosto e o sujeito fiel exorcizado. Nos esquemas de interlocução, que são sempre, sublinha Ribeiro, assimétricos, figura um outro sujeito ou uma outra posição sujeito: Deus. O sujeito fiel quase não intervém como sujeito-falante, é pela voz do bispo que o fiel fala com Deus.

A primeira seção do ritual estudado é sobre a invocação do Espírito Santo. É essencial para colocar o caráter ilusório da reversibilidade do discurso religioso. Essa demonstração, entretanto, não é feliz, ao menos se não 
nos limitamosa uma leituraem termos de locutorou de interlocução. Mesmo se a análise das seqüências seguintes demonstre o contrário do que pretende: "Assim, nas relações de força subjacentes a essa interlocução, a voz do locutor é associada à voz de Deus, e a imagem que os sujeitos fiéis fazem do sujeito bispo é aquela de representante da palavra divina, guiada pela intervenção do Espírito Santo. É preciso esclarecer sempre que tal poder de levar a cabo essas atribuiçōes (invocar a divindade, ditar as normas de contato com a divindade) não advém do bispo enquanto sujeito psicológico capaz de estabelecer estratégias retóricas, mas que, antes, tal poder se instaura na própria enunciação da afirmação desse poder; ato que, partindo de uma FD na sua relação com o interdiscurso, produz o bispo para os fiéis enquanto representante da voz divina e, portanto, dotado de certa legitimidade contra o en costo"

O autor afirma com justiça que o poder de bem conduzir as atribuições - o poder modal - se instaura na própria enunciação. A partir disso, como manter um raciocínio em termos de não-reversibilidade, quando é a enunciação ela mesma que distribui o poder de falar no nome de Deus. Devemos sublinhar que não é o estatuto de bispo, nem de pastor, que assegura esse poder. Além disso, freqüentemente, um pastor auxiliar ou mesmo um obreiro toma o lugar do pastor ou do bispo em uma seqüência do culto.

A segunda seção do ritual é analisada em um parágrafo intitulado "a in terpelação da alteridade: simulacro e possessão". Ribei ro prod uz uma bela análise onde enfatiza a construção do imaginário do fiel "com necessidades”. Essa construção se apóia sobre um “já-lá”, um pré-construído, próprio de FD2. O mal é incrustado no coração dos fiéis através do medo, da insônia, do vício que não conseguem abandonar. A realidade desse mal é reconhecida no discurso do bispo pela repetição de "vocês que": "Você que é uma pessoa que é vítima dos Encostos”. É esse pré-construído que faz aparecer o imaginário do fiel "com necessidades".

Coloca-se aqui a questão de saber se um imaginário pode ser tratado em termos de simulacro. Um imaginário é um reenvio de sentido a novas significaçōes. Os fiéis vivem em situação de miséria e de aflição. A construção do imaginário do fiel com necessidades funciona com base na aceita- 
ção, por parte do fiel, do fato que possui um mal, efetuada pela interpelação "vocês que". Um novo reenvio de significação surge quando a vida do fiel se transforma: ele precisa de saúde. Por que fazer um julgamento de caráter ontológico e afirmar que esse imaginário não passa de simulacro, ou seja, é qualquer coisa que se apresenta falsamente por realidade?

Na relação entre o bispo e o encosto, o pré-construído funda o espetáculo, mas o fiel é inscrito como co-enunciador, pois se o bispo se dirige ao encosto, seu público é constituído pelos fiéis. $\mathrm{O}$ espetáculo funciona na medida em que os fiéis são plenamente co-enunciadores, que sejam como "já-lá" na enunciação. O espetáculo dá assim uma consistên cia ao imaginário do fiel que precisa de salvação.

A terceira seção do ritual é a do ato de exorcismo. Nessa seção o diálogo fica mais cerrado e coloca em cena, através da voz do bispo, aquela do Espírito Santo, único capaz de fazer frente à força de Satã, que se apresenta então como entidades das religiōes afro. $\mathrm{O}$ interrogatório inquisitorial não deixa aparentemente nenhum lugar para o co-enunciador fiel. Nesse interrogatório fechado, nesse tecido suturado, Ribeiro vê se perfilar um outro discurso, um discurso de transgressão, que se transforma em alteração no próprio discurso. Nessa alteração, idéia retomada por Ribeiro com referência a de Certeau, em sua célebre análise das possuídas de um convento de Ursulinas no século XVI, um novo lugar é dado ao co-enunciador. No exorcismo, o fiel se encontra re-incorporado ao discurso. Não há portanto não reversibilidade. Ao contrário, o discurso funciona na medida em que essa reincorporação se faz. A repetiçãoincessante do espetáculode exorcismoproduzido há alguns anos no culto de terça-feira (anteriormente consagrado à cura divina) parece indicar o sucesso da montagem discursiva do exorcismo.

A quarta parte conduz ao coração da análise e culmina na liberação. Intitulada em seu primeiro segmento de "Resistência ao simulacro ou simulacro da resistência", essa seção coloca a questão da alteridade e faz emergir um julgamento de valor sobre o neo-pentecostalismo. Esse, "longe de representar o ecumenismo e a tolerância, é a acusação da presença ativa da alteridade", diz o autor. Mas é aqui que um recurso à literatura sobre o religioso faz falta à análise.

Debates do NER, Porto Alegre, ano 6, N. 7, p. 115-124, JAN./Jun. 2005 
O religioso pode ser tratado em suas relações extremamente variadas com relaçãoà alteridade(Gauchet, 1985). Da alteridaderadical da imanência religiosa primeira à alteridade da "saída da religião" que coloca o divino na exterioridade, deixando todo lugar à elaboração da subjetividade, o religioso é compatível com inúmeras formas de alteridade. Afirmar com base em uma análise, centrada sobre in terlocuçōes, que o "neopen tecostalismo" é "a acusação da presença ativa da alteridade" não tem fundamentação.

O neopentecostalismo, se quisermos manter essa fórmula, pode parecer afogar a alteridade, pois produz discursivamente um discurso da imanência, mas nesse discurso intervém um sagrado. Esse não é, na análise de Ribeiro, reconhecido. Ao contrário, essa análise se contradiz quando envia à noção de ilusão. É verdade que "a possessão é o lugar do dizer do excluído, do mau sujeito, do efeito de retorno de saber que transgride a Lei” e que há u ma espetacularização da reversibilidade. Esse espetáculo não se conclui com o silêncio do diabo no momento da liberação. Diferentemente das formaçôes ideológicas do cristianismo clássico que estiveram sempre em conflito com as religiões afro, mas a título de luta contra a superstição, o "neopentecostalismo" consegue identificar não somente às entidades dos cultos afro ao mal, mas também à pobreza, à doença e ao vício. O espetáculo do fiel possuído é aquele da degradação psicológica e material. É a imagem dessa degradação que é mostrada e depois remediada pelo ritual de libertação.

Voltamos assim ao ponto de partida de meu comentário. Embora o autor parta do ponto de vista da heterogeneidade, o fato de limitar a análise ao jogo de duas formaçôes discursivas o conduz progressivamen te para a repetição de pressupostos sobre a não-reversibilidade e sobre a noção de simulacro e ilusão. Essa redução é tão forte que o autor se centra mais nos interlocutores do que nos enunciadores e parte de uma definição de formação discursiva inicialmente marcada pela homogeneidade das posições ideológicas. 


\section{REFERÊNCIAS}

CASTORIADIS, Cornelius, Do maines de l'homme: Les carrefours du labyrin the, Paris, Seuil/ Essais, 1986.

GAUCHET, Marcel, Le désenchantement du monde: Une histoire politique de la religion, Paris, Gallimard, 1985.

Debates do NER, Porto Alegre, ano 6, N. 7, p. 115-124, jan./Jun. 2005 